\title{
DESFAMILIARIZAÇÃO E FICÇÃO CIENTÍFICA: UMA ABORDAGEM DE BASE SCHRÖDINGERIANA À CONSTRUÇÁO DO OBJETO LITERÁRIO
}

\author{
Caroline Elisa Murr $^{1}$
}

\begin{abstract}
Resumo: $\mathrm{O}$ presente artigo aborda a construção dos objetos literários na experiência humana, com base nas ideias de Schrödinger sobre a construçấo da realidade, publicadas entre 1928 e 1964. Sugere-se relacionar a construção de tais objetos aos processos de resgate de invariantes e de construção de objetos científicos, na abordagem schrödingeriana. No entanto, nota-se que essa abordagem não é suficiente para explicar certos casos. Assim, propóe-se adicionar a conceituação de desfamiliarização, concebida por Shklovsky, em 1917, e revisitada por Banes, em 2003. Essa concepçâo consiste basicamente em tornar estranho o que é familiar, provocando a atenção na sua direção e despertando a consciência, através de uma experiência marcante. A desfamiliarização mostra-se adequada para descrever momentos em que há quebra de expectativas e resgate de sensaçôes. Este trabalho explora, ainda, exemplos que ilustram esses processos, examinando trechos de obras de H. G. Wells e enfatizando os objetos científicos que são resgatados na ficção. Esta análise evidencia que tais objetos passam por desfamiliarização, embora de forma distinta dos objetos cotidianos. Além disso, alguns dos trechos ressaltados sugerem que a desfamiliarização é acentuada na leitura de ficção científica.
\end{abstract}

Palavras-chave: Schrödinger. Invariantes. Desfamiliarização. Ficção científica. H. G. Wells.

\section{INTRODUÇÃo}

Neste artigo, tomam-se como base as ideias de Schrödinger sobre a construção da realidade, para investigar como são construídos os objetos, no contexto da literatura de ficção. Em seus escritos filosóficos, Schrödinger não abordou objetos nessa esfera, mas é possível partir de suas especulações sobre a realidade, nos âmbitos cotidiano e científico, a fim de estudar a construção do objeto, na experiência de fruição literária. O foco é a literatura de ficção em prosa, em especial a ficção científica, destacando algumas obras

${ }^{1}$ Universidade Federal de Santa Catarina, Florianópolis, SC - Brasil. (D) https://orcid.org/0000-00029936-4247 E-mail: caromurr@gmail.com

http://doi.org/10.1590/0101-3173.2020.v43n3.03.p35

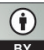


do escritor britânico H. G. Wells. Serão tomadas como exemplos duas obras que representam bem as características que se pretende enfatizar: The Time Machine e The Invisible Man.

Na próxima seção deste texto, será feito um resumo da terminologia schrödingeriana a ser utilizada, bem como das ideias centrais da abordagem de Schrödinger que serão aqui aproveitadas. Não se trata, no entanto, de um texto sobre as ideias de Schrödinger; estas já foram expostas e abordadas em detalhes, em outros trabalhos ${ }^{2}$. O objetivo deste artigo vai além, introduzindo o conceito de desfamiliarização para explicar a construçáo de objetos literários, especialmente no contexto da ficção científica. Na maior parte dos casos, a construção parece se dar de forma semelhante à que Schrödinger descreve para os objetos científicos, pois a leitura revisita invariantes cotidianos e científicos, afastando-se deles posteriormente. Com os invariantes, as expectativas também são retomadas, mas, em alguns casos, essas expectativas são alteradas; em outros, a construção exige uma volta ao âmbito das sensações. No momento da leitura, está-se longe do objeto empírico cotidiano, todavia, é possível afirmar que a desfamiliarização permite acessar sensaçôes que dele ficaram, dentro do invariante construído. Esses casos, que serão estudados neste artigo, como que reabrem os invariantes, revisitam as sensaçóes e, por vezes, modificam algo na constituição do objeto.

Nas seçôes seguintes, o tema da desfamiliarização é introduzido, fazendose conexôes com a abordagem de Schrödinger. Em seguida, apresenta-se uma nova abordagem à construção dos objetos da literatura, não mencionada por Schrödinger. Por fim, enfatiza-se o caso da ficção científica, explorando alguns exemplos de trechos dos textos selecionados que ilustram a argumentação aqui exposta sobre o processo de desfamiliarização, na leitura de obras desse gênero.

\section{A CONSTRUÇÃo da REALIDAde SEgUndo SCHRÖDINGER: IDEIAS CENTRAiS}

Ao longo de seus escritos filosóficos, Erwin Schrödinger sugere que os objetos cotidianos e científicos são construídos de maneiras diferentes. Os cotidianos são construídos a partir de sensações e expectativas, enquanto os científicos, apenas de expectativas (SCHRÖDINGER, 1928, p. 119125). Além disso, depois de feita a construção dos objetos cotidianos, após suficientes interaçóes, são criados os invariantes, os quais permitem que não

2 Ver Murr, 2010, cap. 3, seções 3.2 e 3.3 e Murr, 2014, cap. 1, seção 1.2, para um desenvolvimento comentado das ideias de Schrödinger sobre a construçấo dos objetos. 
seja preciso reconstruir os objetos a cada nova experiência com eles, tornando mecanizado o seu uso (SCHRÖDINGER, 1954a, p. 146-148).

Nas obras em que explica tais formulações, o objetivo de Schrödinger é discutir a realidade científica, mais precisamente, os objetos científicos. Para isso, ele faz um desvio pelo objeto cotidiano, o que resultou em suas ideias sobre a construção da realidade cotidiana. Além disso, explicar a formação e a realidade dos objetos científicos a partir dos cotidianos faz com que a construção dos objetos científicos dependa dos objetos cotidianos. Pode-se dizer, assim, que sua realidade também é dependente deles.

A abordagem schrödingeriana sobre a construção da realidade, nos contextos cotidiano e científico, possui outras nuances, mas o objetivo aqui não é fazer uma exposição alongada de seus detalhes. A seguir, suas ideias centrais, necessárias a esta argumentação, serão brevemente expostas, dando ênfase aos tópicos de interesse para este artigo.

Schrödinger (1928, p. 119) exemplifica, neste trecho, a constituição dos objetos cotidianos:

Uma análise mais exata mostra que essa cesta de frutas é, na realidade, nada mais que uma configuração, a qual serve para unir certas percepçōes sensoriais, algumas das quais são reais, enquanto que a maioria é apenas virtual, e antecipamos suas ocasionais ocorrências em relaçōes definidas umas com as outras.

Esse trecho condensa os dois aspectos fundamentais dos objetos, para Schrödinger: as percepçóes reais e as percepçóes virtuais, ou expectativas. As reais equivalem às sensaçóes diretamente causadas pelo contato com o objeto empírico, enquanto as virtuais equivalem a expectativas com relaçáo a eles. Mais tardiamente, em outra obra, ele elabora sua argumentação sobre as expectativas as quais mencionava, em 1928:

[...] como objeto material [este braço] não é composto somente de sensaçóes diretas que eu tenho, mas também de sensaçôes imaginadas que eu teria se o fizesse virar, se o deslocasse, se o visse sob todos os ângulos; além disso, ele é composto de percepçôes que, segundo o que imagino, você tem dele (SCHRÖDINGER, 1954b, p. 94).

De acordo com Schrödinger (1951), a construçáo de muitos objetos da ciência parte dos objetos cotidianos, mas depois se afasta da fonte das 
sensaçôes, e estes acabam constituídos apenas do que ele chama, por vezes, de percepçóes virtuais, por vezes, de expectativas. No contexto científico, no entanto, essas expectativas são modificadas com relação ao mesmo objeto na vida comum. As teorias e leis científicas as alteram, gerando, portanto, um objeto completamente diferente, tanto no processo de construção quanto na sua constituição.

Outro ponto importante a ser salientado na abordagem schrödingeriana, tendo em vista o uso que dele será feito, neste texto, é o conceito de invariante. Os invariantes são, grosso modo, os objetos e eventos em comum para todos os sujeitos:

[...] a formação de invariantes é um comportamento que adotamos desde

a mais tenra infância, desenvolvemos à mais alta perfeição, e usamos a todo minuto desperto de nossas vidas, para nos orientar nas coisas que nos rodeiam diariamente (SCHRÖDINGER, 1954a, p. 146).

Iniciados individualmente, os invariantes estendem-se para a mutualidade, entre indivíduos que mantêm contato social direto. Schrödinger assinala que esse processo começa com nosso corpo e nosso entorno, sendo que os primeiros invariantes envolveriam a aquisição de noções geométricas, como forma, rigidez e movimento (SCHRÖDINGER, 1954a, p. 148). Invariantes podem ser tanto noçóes quanto os próprios objetos, sendo que esta última acepção será ressaltada neste artigo. Por exemplo, considere-se um objeto, como o sol, ou a luz, ou uma mesa, ou uma árvore. Estes constituem invariantes, porque todos os indivíduos que vivem sob um mesmo contexto social precisam estar de acordo sobre eles, ao menos sobre sua configuração básica.

Após essa breve exposição sobre os pontos centrais da abordagem schrödingeriana, segue-se uma análise da concepção de desfamiliarização, a qual será utilizada, em seguida, para fundamentar a construção do objeto literário, inspirando-se no processo descrito por Schrödinger para os outros tipos de objetos.

\section{DeSFAMILIARIZAÇÁO: ALGUMAS ABORDAGENS AO CONCEITO}

Nesta seção, serão brevemente expostas as ideias de três autores sobre a desfamiliarização: Elgin, Banes e finalmente Shklovsky, proponente original do conceito na literatura. A abordagem de Elgin é empregada aqui com o 
intuito de introduzir e apoiar as ideias de Banes sobre o tema, representando uma visão mais contemporânea e também mais ampla dessa concepção. Por sua vez, trata-se de Shklovsky, com o objetivo não só de compreender a posição de Banes, que se baseia no autor russo, como também de resgatar a abordagem original ao tema.

A filósofa americana Catherine Elgin, em um artigo de 2011, faz uso de concepçôes que vêm da estética, mais especificamente do filósofo Nelson Goodman, aplicando-as a discussóes em filosofia da ciência. Nesse artigo, Elgin menciona também o tema da desfamiliarização. Esta é a ideia central do conceito de desfamiliarização, na interpretação de autores como Banes (2003) e Elgin (2011): tornar estranho o que é familiar, provocando a atenção na sua direção. Esse processo parece ocorrer com objetos que são retirados de uma condição cotidiana e levados ao status de obras de arte. Assim, eles passam a provocar reaçóes que antes, quando se tinha familiaridade com eles, não provocavam.

Nesta passagem, o processo de provocar a atenção e trazer à consciência algo que foi automatizado é destacado:

Quando algo é familiar, estamos tão acostumados a isso que não focamos nisso ou atentamos para isso. Um olhar de passagem nos permite reconhecê-lo pelo que é e então ir em frente. A desfamiliarização aumenta a consciência de coisas que são táo óbvias que rotineiramente as ignoramos. Nós andamos, corremos, subimos e vemos outros fazendo as mesmas coisas, sem pensar muito a respeito (ELGIN, 2011, p. 403, tradução nossa)

Pode-se sustentar que a desfamiliarização devolve à consciência elementos que já haviam sido tirados de foco. No entanto, estes não têm mais a mesma caracterização nem categorização após essa mudança de contexto. Em certos casos, esses elementos passam a ter o status de obras de arte, despertando expectativas relacionadas à apreciaçáo e à relação dos sujeitos com a esfera da arte.

A desfamiliarização sempre existiu, em certa medida, nas artes. Contudo, certas tendências artísticas acentuam essa característica, colocando no contexto da arte objetos cotidianos, como caixas de palha de aço, no caso da obra "Brillo Box (Soap Pads)", de Andy Warhol (Warhol, 1964). Visando a estudar casos como o de Warhol, Banes expande o conceito de Shklovsky, afirmando que este pode aparecer na arte de duas formas, as quais ela explica 
e desenvolve. No escopo do presente artigo, apenas a primeira dessas formas é trabalhada:

Parece-me que, expandindo Shklovsky, o termo "desfamiliarização" pode incluir dois lados de uma mesma moeda: tornar estranhas as coisas familiares e tornar familiares as coisas estranhas (BANES, 2003, p. 5, tradução nossa, ênfase da autora).

Conforme Banes, no caso da Pop Art, há uma mudança de contexto; o objetivo de Warhol seria percebermos como "uma caixa de Brillo, ou a réplica de uma, tornou-se ela própria uma obra de arte na galeria" (BANES, 2003, p. 9, tradução nossa). A autora ainda ressalta que a visão de Warhol com relação à Pop Art era de que esta "treina alguém para retornar à própria vida com uma nova apreciação do familiar." (BANES, 2003, p. 10, tradução nossa). A autora identifica essa mudança com a desfamiliarização, revisitando e expandindo o conceito de Shklovsky.

Viktor Shklovsky, em seu livro Theory of prose, de 1917, propóe o termo ostraniene, na análise literária, traduzido do russo para o inglês no artigo de 1965, consultado por Banes (2003, p. 4, nota 2), como defamiliarization. O uso do termo em inglês, a partir dessa tradução, pode ter sido responsável pela interpretação dos filósofos norte-americanos, como Banes. Segundo Banes (2003, p. 4), mesmo antes de essa tradução de 1965 ter sido publicada, nos Estados Unidos, as vanguardas artísticas já haviam sido influenciadas por essa noção.

Por outro lado, na tradução para o inglês de 1990, feita por Benjamin Sher, ostraniene foi traduzido como estrangement (SHKLOVSKY, 1917, p. 6), que, no português, parece mais próximo a "estranhamento", termo usado nos estudos literários, referindo-se ao conceito de Shklovsky³. O tradutor explica, no prefácio ao livro de Shklovsky, sua escolha em mudar a tradução anterior de defamiliarization para enstrangement. Em primeiro lugar, para Sher, "a palavra russa ostraniene (substantivo) ou ostranit' (verbo) é um neologismo." (SHER, 1990, p. xviii, grifo do autor). Deveria, portanto, ser traduzida também por um neologismo. Além disso, para ele,

Sklovsky fala de ostraniene como um processo ou ato que envolve um objeto ou imagem com "estranhamento", ao "removê-los" da rede de percepçôes e expressōes linguísticas convencionais, formulaicas, estereotípicas (SHER, 1990, p. xix, tradução nossa, grifos e ênfases do autor).

\footnotetext{
${ }^{3}$ Ver, por exemplo, o dossiê sobre estranhamento na literatura, em Passos et al., 2015.
} 
Até aqui, essa descrição se parece com a noção de desfamiliarização abordada por Banes e Elgin. Sher discorda do uso do termo, entretanto, explicando que este levaria a um entendimento errado do conceito, pois não se trataria de uma transição do familiar para o desconhecido, mas sim daquilo que já se encontra no nível do conhecido cognitivamente, isto é, na regiáo da economia de esforço mental, para o realmente conhecido, que expande e complica o processo da percepção (SHER, 1990, p. xix). A interpretação de Sher parece adequada, mas não impede o uso de "desfamiliarizaçáo", já que "estranhamento" também pode ter a conotação de transição para o desconhecido, no português. Além disso, o uso do correlato "estranhamento", no português, não segue a ideia de neologismo do tradutor, o qual afirma que estrangement tampouco é um termo adequado no inglês (SHER, 1990, p. xix).

Levando em conta essas razões, neste artigo, faz-se opção por utilizar a tradução do termo usado por Banes, "desfamiliarização". Como se trata de um neologismo no português, esse uso estaria mais de acordo com a ideia original de Shklovsky, além de absorver a apropriação do termo para uso na arte em geral, que é a ideia de Banes. Nosso intuito é ter em mente a passagem do familiar para outra esfera, seja científica, seja ficcional, o que é facilitado pela manutenção da raiz de "familiar". Na ficção científica, o familiar muda de contexto, reorganizando-se as relaçóes entre seus elementos e causando o estranhamento que nos faz refletir não só sobre noçôes cotidianas, mas também sobre conceitos científicos. O termo "desfamiliarização" parece ser adequado, já que entendemos como familiar aquilo que já passou ao inconsciente e à mecanização da vida cotidiana ou das teorias científicas. A arte, portanto, "desfamiliariza", no sentido de retirar o véu da familiaridade ${ }^{4}$.

\section{DesfamiliarizaÇáo E A abordagem SCHRÖDINGERIANA: PONTOS DE CONTATO}

Segundo Shklovsky (1917, p. 12), a desfamiliarização na literatura engendra um paralelismo psicológico, cujo intuito é transferir um objeto de sua esfera de percepção usual para uma outra. Essa transferência pode ser interpretada, na abordagem schrödingeriana, como a quebra de expectativas causada pelo que é novo e diferente, na percepção. É importante salientar que

\footnotetext{
${ }^{4}$ A expressão "retirar o véu da familiaridade" é de John Dewey, referindo-se à experiência estética (cf. Dewey, 1934, p. 108). Muitas conexóes podem ser notadas entre o conceito de experiência estética e o de desfamiliarização, mas essa aproximação foge ao escopo deste artigo.
} 
a construção de objetos literários em geral é uma mudança de contexto, do cotidiano para o literário ou do científico para o literário. No entanto, não é sempre que essa construção causa estranhamento. É preciso que haja esse paralelismo psicológico; em uma abordagem schrödingeriana, que haja quebra de expectativas, as quais despertam a atenção.

Pode-se argumentar que as reaçóes diferenciadas causadas pela desfamiliarização seriam consequências de uma alteração nas expectativas ou conexôes causais com relação aos elementos desfamiliarizados. Para Schrödinger, a construção dos objetos envolve, além de percepçóes reais e virtuais, expectativas, conforme já foi salientado anteriormente. Portanto, alterá-las mudaria também a ontologia dos objetos. Essa ideia é harmônica com a concepçáo schrödingeriana de que o aumento do grau de familiaridade com os objetos é responsável pela automatização das expectativas (SCHRÖDINGER, 1957, p. 208). Quanto mais familiaridade com um objeto, mais as expectativas com relação a ele são automatizadas, não sendo necessário construí-lo novamente a cada situação, mas apenas fazer um resgate de invariantes. É coerente dizer que, do ponto de vista schrödingeriano, o que foi familiarizado é levado à inconsciência, devido à automatização. Assim, expectativas familiares não seriam capazes de despertar certas sensações, as quais só estariam presentes nos primórdios da construçáo de um objeto. A desfamiliarização mudaria essas expectativas, surpreendendo e trazendo à consciência objetos que já se tornaram familiares. A desfamiliarização de objetos e outros elementos do cotidiano gera um reencontro com os mesmos, produzindo relaçóes que não aparecem, no contexto usual.

Segundo Schrödinger (1956, p. 98-99; 1957 p. 208), o comportamento que é automatizado e o objeto com que temos profunda familiaridade não nos despertam mais a consciência ${ }^{5}$. É possível relacionar essa perspectiva com a de Shklovsky. Em "Art as Device”, ele afirma que, em geral, na percepção habitual, que se torna automática, usamos uma "economia de esforço mental": "Depois de percebidos várias vezes, os objetos adquirem status de reconhecimento" (SHKLOVSKY, 1917, p. 6, tradução nossa). Apenas "reconhecemos" os objetos, nesses casos, e enxergamos somente a sua superfície. Essa explicação se parece com a abordagem schrödingeriana do resgate de invariantes, o qual é justamente uma questão de economia de esforço e de reconhecimento, após contato saturado com o objeto.

\footnotetext{
${ }^{5}$ Sugere-se, em Murr, 2014, que ideia semelhante aparece em Russell (ver Murr, 2014, p. 164; e Russell, [1921], p. 214). Somente o que é novo participa da vida consciente, em uma interpretação desses dois autores.
} 
Shklovsky cita uma passagem do diário de Tolstói que trata dessa excessiva automatização na vida cotidiana e também da ligação com o tema da consciência: "Se a vida complexa de muitas pessoas acontece inteiramente no nível do inconsciente, então é como se essa vida nunca tivesse sido vivida." (TOLSTÓI, apud SHKLOVSKY, 1917, p. 5, tradução nossa). Para Schklovsky, a automatização de certa forma "destrói" as coisas ${ }^{6}$. Pode-se dizer que a mecanização da percepção destrói a própria vida, a qual, não tendo sido consciente, como declara Tolstói, não teria sido de fato vivida.

Conforme Shklovsky, o escape desse processo para o ser humano está na arte. Em especial, a desfamiliarização é responsável por nos fazer sentir novamente os objetos, deixando a percepção mais longa, mais trabalhosa. Através desse processo, removemos o objeto da esfera da percepção automatizada (Shklovsky, 1917, p. 5-6). Além disso, Shklovsky insiste em que a percepção, dessa forma, faz com que "vejamos" o objeto, ao invés de apenas reconhecê-lo. Ele afirma:

E então, a fim de fazer retornar a sensação aos nossos membros, a fim de nos fazer sentir os objetos, de fazer uma pedra ser sentida como pedra, ao ser humano foi dada a ferramenta da arte. O objetivo da arte, pois, é nos levar ao conhecimento de uma coisa através do órgão da visão, ao invés de reconhecimento. "Desfamiliarizando" objetos e complicando a forma, o dispositivo da arte torna a percepção longa e "laboriosa". O processo de percepção na arte tem um propósito todo seu e deve ser estendido ao máximo (SHKLOVSKY, 1917, p. 6, grifos do autor, tradução nossa)

Shklovsky (1917, p. 10 e 12) refere-se a "ver" o objeto, remetendo ao "órgão da visão". Mais adiante, ele destaca o papel das imagens, na literatura, sendo que este seria o de chegar a uma "visão" dos objetos, ultrapassando o mero reconhecimento. Segundo ele, o objeto é trazido à "visão" por causa da capacidade do tipo de paralelismo psicológico provocado pela desfamiliarização em fazer o leitor parar e lutar com o texto. Após essa luta, o objeto é trazido à visão ou, pode-se dizer, à consciência. Sugerimos que esse processo vai além de somente formar uma imagem, o que já nos daria acesso às sensaçóes, mas se constitui em revisitar várias sensaçôes presentes no objeto, as quais passam despercebidas, quando estamos apenas reconhecendo invariantes.

Banes (203) reforça essas ideias, compreendendo a desfamiliarização como uma estratégia adotada para revigorar a percepção. Segundo ela,

${ }^{6}$ A expressão em inglês é automatization eats away things (cf. Shklovsky, 1917, p. 5). 
os artistas usam várias estratégias para prolongar a percepção e restaurar a visão, a qual foi embotada pelo conhecimento ${ }^{7}$. Para Banes, a arte revigora a vida, e o processo de desfamiliarização é uma das formas de se fazer isso. Ela ressalta também os aspectos político e moral do processo. A arte acorda do automatismo, não só em relação à percepção embotada dos objetos, mas também do automatismo entorpecedor, o qual tem um efeito político e moral, assinala Banes (2003). Seus exemplos de espetáculos de vanguarda na dança dos anos 1960, em Nova Iorque, perpassam essas preocupaçóes. Ela afirma que essas vanguardas tinham motivaçóes políticas e morais, de sorte que ajudaram a quebrar muitas barreiras e a trazer à consciência muitas questóes importantes para a sociedade (BANES, 2003, p. 18).

\section{A CONSTRUÇÁo dos ObJETOS CIENTíficos: O CASO DA LUZ}

Nesta seção, a fim de ilustrar as ideias acima apresentadas, enfatizam-se as caracterizaçóes cotidiana e científica da luz, exemplo que será empregado também nas análises de trechos literários mais adiante.

O conceito de luz foi alvo de várias controvérsias, ao longo da história da ciência, especialmente no início do desenvolvimento da física quântica, podendo revelar muito sobre a relação entre objetos cotidianos e científicos ${ }^{8}$. Comparando a relação cotidiana que temos com a luz à sua conceituação científica, nota-se uma mudança de status, a qual aparece de maneira explícita após a revolução quântica.

As primeiras investigaçóes científicas envolvendo a luz parecem girar em torno do problema da ação à distância. Por exemplo, "como a luz do Sol alcança a Terra?” era uma pergunta que intrigava os cientistas. Duas escolas alternaram-se, na história da física, para responder a essa questáo: uma asseverando a natureza ondulatória da luz e outra, a sua natureza corpuscular. Newton era adepto desta última, e sua influência fez com que esse fosse o paradigma dominante até o século XIX (ASIMOV, 1966, p. 65).

Ao mesmo tempo, como a luz era compreendida do ponto de vista cotidiano? Certamente, não da mesma forma que na ciência. Enquanto a luz

\footnotetext{
${ }^{7}$ Parece que a autora se refere ao que Shklovsky chama de "reconhecimento".

8 Sobre a conceituação física da luz, no decorrer da história da ciência, ver Asimov, 1966. O livro de Asimov, apesar de menos conhecido do que outras histórias da física, é de extrema qualidade em seu conteúdo e serve bem aos propósitos deste trabalho, tendo sido escolhido, considerando-se sua proximidade com a ficção científica e a clareza de suas explicações.
} 
estava sendo cientificamente investigada em sua composição, essa investigação não era tâo importante no senso comum. A luz enquanto objeto cotidiano seria, segundo Schrödinger, construída a partir de dois componentes: sensaçôes - o que vemos e sentimos, por exemplo - e expectativas - as quais expressam, em última instância, suas funçóes na vida cotidiana, ou seja, o que se espera desses objetos. A luz cotidiana significa calor, segurança (em oposição à escuridão), possibilidade de levar a cabo as tarefas cotidianas etc. Nesse sentido, a luz, ou qualquer outro objeto cotidiano, é caracterizado por suas consequências ou tarefas que permite cumprir - como ver, que é a primeira e mais importante atividade que a luz permite executar.

Por outro lado, investigaçôes científicas sobre a luz contribuíram para o desenvolvimento de diversos instrumentos, como espelhos, lentes e o telescópio. Por sua vez, esses artefatos levaram a mais e mais descobertas sobre a luz científica. A luz científica é construída, de acordo com uma perspectiva schrödingeriana, apenas por meio de percepçóes virtuais, ou expectativas. Quando uma teoria é sugerida sobre a luz, cientistas experimentam com um objeto construído como luz, esperando certos resultados. É importante notar, no entanto, que já não se trata das mesmas expectativas sobre a luz, na vida cotidiana. É razoável concluir que a luz cotidiana e a luz científica não são o mesmo objeto, de acordo com essa argumentação.

Após analisar esse exemplo de construção de objeto científico, a partir de seu equivalente cotidiano, a seção seguinte trata de avançar para além da abordagem de Schrödinger e de sua interpretação. Inicia-se, por conseguinte, um desdobramento que toma como base as ideias expostas anteriormente, a fim de propor uma abordagem para o processo de construçáo dos objetos literários. É preciso incluir a experiência da desfamiliarização, nessa caracterização, uma vez que esta difere das construçóes anteriores, pois se constitui em experiência estética e lida com objetos artísticos. O caso da luz será retomado mais adiante, de modo a ilustrar a aplicação de tais ideias em exemplos da própria literatura, enfatizando seu papel enquanto objeto científico, e também cotidiano, nas obras literárias. Todavia, este não é o único exemplo a ser utilizado; outros serão analisados, a fim de fornecer uma visão mais completa do processo que se pretende exemplificar. 


\section{CONSTRUÇÃo DOS OBJETOS LITERÁRIOS}

Para explicar essa construção, o modelo schrödingeriano exposto anteriormente será tomado como base, pressupondo-se que os mesmos padróes que seguimos para construir a realidade cotidiana e também a científica são usados, repetidos e modificados, quando da construção dos objetos e contextos da literatura enquanto experiência artística ${ }^{9}$. Além disso, sugere-se aqui que a desfamiliarização é um processo necessário para explicar a construção da esfera literária, pois é através dela que fazemos uma revisão das expectativas e revisitamos as sensaçóes que são parte dos invariantes dos objetos. A desfamiliarização constitui o momento que mais caracteriza a leitura de literatura como experiência estética, tornando-a tão singular e marcante. Conforme Shklovsky (1917, p. 12), é quando a literatura alcança seu maior e mais duradouro impacto.

Antes de partir para essa análise, é necessário discutir um ponto no qual parece haver atrito entre a abordagem da desfamiliarização e algumas afirmaçôes de Schrödinger. Ele argumenta que os objetos do âmbito científico não são os mesmos que os objetos do cotidiano. Quando a ciência aborda o Sol, por exemplo, toma o seu invariante, muda algumas expectativas nele e abandona as sensações, passando a ser constituído apenas de pura configuração, ou percepçóes virtuais. A desfamiliarização sugere que os objetos são retirados de um contexto e colocados em outro; por exemplo, do cotidiano para a literatura, ou da ciência para a literatura. Porém, a abordagem de Schrödinger possibilita identificar a desfamiliarização com a quebra ou modificação de expectativas que constituem o objeto. A quebra de expectativas, por sua vez, altera a ontologia dos objetos. Pode-se afirmar, portanto, que os objetos que construímos na literatura não são os mesmos que os cotidianos ou os científicos.

Construir o contexto de uma obra de arte, no caso de um livro, segue um processo parecido com o descrito para a construção da realidade cotidiana, na abordagem aqui adotada. Mas, enquanto lemos, não estamos tendo contato direto com o mundo empírico; por isso, não formamos novas sensaçôes. Logo, os objetos literários não são de mesma constituição que os cotidianos. Tampouco são puros invariantes ou puras configurações, somente, como os científicos.

\footnotetext{
9 Já mencionamos uma aproximação da desfamiliarização com conceitos de Dewey, sendo que as mençôes a experiência estética e obra de arte, bem como objeto artístico, seguem as suas concepçôes, em Art as Experience (1934).
} 
De acordo com Schrödinger, a experiência e o contato com o mundo nos fazem construir a realidade cotidiana. Uma vez construída sua base central, alguns invariantes são mantidos para resgate imediato, quando outro contato é necessário com o objeto. Esse contato pode ser lembrar-se, simplesmente, do objeto. Na leitura de literatura, resgatamos muitos invariantes para construir o contexto da obra, como se estivéssemos nos lembrando dos objetos. Se fosse apenas isso, a leitura não seria uma experiência diferente da lembrança em geral. Mas há momentos que nos envolvem mais ativamente na construção dos objetos literários, da mesma maneira que em obras de arte de outros tipos: as ocorrências da desfamiliarização. Esses momentos parecem alterar as expectativas que ajudam a constituir os objetos e exigem que se retome a construção, como se fosse a primeira vez que temos contato com eles. Assim, a consciência é ativada, a atenção se volta para esse objeto, a experiência é mais profunda e as conexóes usuais com outros objetos do contexto nos quais eles sempre apareciam são quebradas. $\mathrm{O}$ objeto em questáo, além de colocado no contexto da arte, ainda é deslocado de contexto no livro, fazendo-nos experienciá-lo novamente e reconstruí-lo.

Ao abrir os invariantes e repensar sua configuração, revendo as expectativas que os compóem, chegamos perto novamente das sensaçóes que estão presentes nessa configuração do objeto cotidiano. Nesse sentido, o processo parece semelhante ao que ocorre, quando da construção de parte dos objetos científicos. Por vezes, tomam-se invariantes cotidianos e mudam-se expectativas dentro deles, dando ao objeto nova configuração, sendo que a nova construção resultante é constituída apenas de expectativas. Nesse caso, as sensações são abandonadas.

A fim de ilustrar com mais clareza essa argumentação, são explorados, a seguir, alguns exemplos que reforçam essas afirmaçóes.

\section{DeSFAMILIARIZAÇÁO NA LITERATURA: ALGUNS EXEMPLOS}

Nos exemplos apresentados a seguir, tanto o resgate de invariantes quanto a desfamiliarização, trazendo quebra de expectativas com relação a objetos cotidianos, podem ser observados. $\mathrm{O}$ estudo da construção dos objetos científicos na ficção científica será analisado na próxima seção.

Em primeiro lugar, tomemos um caso de puro resgate de invariantes. Voltando a usar o exemplo da luz, dois breves trechos, nos quais nossa relação 
cotidiana com a luz aparece, na obra The Invisible Man, de H. G. Wells (1897a), serão examinados.

No segundo capítulo do livro, que apresenta a estadia do homem invisível em uma hospedaria e as reaçóes de seus anfitrióes a seus comportamentos estranhos (Wells, 1897a, cap. 2), o narrador descreve a seguinte cena, na qual a anfitriá se aproxima da porta do cômodo em que está alojado o Homem Invisível:

Ao abri-la, viu que o hóspede estava sentado na poltrona em frente à lareira, aparentemente cochilando, com a cabeça enfaixada pendida para o lado. A única luz do aposento era o brilho vermelho do fogo - que se refletia em seus olhos como sinais de perigo numa ferrovia, deixando nas trevas o rosto caído -, além dos últimos vestígios da luz do dia que entravam pela porta recém-aberta. Tudo sombrio e indistinto, ainda mais aos olhos dela, que acabara de acender o lampiáo. Por um segundo, porém, teve a impressão de que o homem que via tinha uma boca enorme - tão grande que engolia totalmente a porção inferior do rosto, assim, escancarada. Foi uma sensaçáo momentânea: a cabeça enfaixada de branco, os óculos monstruosos e o abismo desproporcional por baixo deles. Mas nesse momento ele se mexeu, endireitou-se na poltrona e ergueu a mão. Ela abriu totalmente a porta para que a sala ficasse mais iluminada e então conseguiu vê-lo melhor, com o lenço cobrindo-lhe o rosto, exatamente como fizera com o guardanapo. Tinha sido enganada pelas sombras, concluiu (WELLS, 1897b, p. 14-15).

Esse trecho enfatiza, de início, o fogo que ardia na lareira nesse aposento, revelando o homem invisível procurando conforto em forma de aquecimento. Um pouco da luz do dia entra, mas, mesmo assim, não o suficiente para que a anfitriã confie nas imagens que seus olhos lhe mostram. Ao ver algo que lhe parece fantasmagórico, isto é, a boca desmedidamente enorme de seu hóspede, ou melhor, um buraco no lugar de sua boca, não tarda a atribuir essa visão à falta de luz. Quando ela deixa mais luz entrar no aposento, sente-se mais segura de seus sentidos.

Pode-se notar aqui a relação cotidiana com a luz, a mesma ressaltada anteriormente: a luz que aquece, que traz conforto, segurança, que nos permite ver e poder confiar em nossa visão. Mais um exemplo que enfatiza a sensação de conforto trazida pela luz pode ser encontrado em um dos capítulos finais do livro: 
Não me sentia seguro ali. Havia muita gente circulando, e resolvi perambular mais um pouco, até que cheguei a uma seção, no andar de cima, que continha centenas de camas, e, atrás delas, encontrei finalmente um lugar para descansar, no meio de uma pilha de colchóes. O lugar era bem iluminado e agradavelmente aquecido, e resolvi ficar ali por um tempo, até a hora de fechar, sempre de olho nos vendedores e clientes que vagavam por perto. Pensei que depois poderia conseguir comida e roupa (WELLS, 1897b, p. 138).

O trecho destacado faz parte do relato da fuga do cientista Griffin, o Homem Invisível, depois de ter sido bem-sucedido no experimento que o leva à invisibilidade (Wells, 1897, p. 154-166). O próprio personagem narra as dificuldades pelas quais passou, em sua fuga, até que o frio começa a ser muito intenso e uma tempestade de neve se aproxima. É nesse contexto que Griffin encontra a loja onde se abriga, e o lugar que considera mais seguro: além de longe das pessoas, é "bem iluminado e aquecido". O personagem alia essa segurança a roupas e comida, os quais terá à sua disposição na loja, encontrando conforto na ideia de que estará seguro ali. Apesar de ter tido seu corpo modificado na relação física com a luz, ele ainda precisa da segurança que a luz cotidiana pode proporcionar, especialmente nesse momento em que se sente extremamente frágil e desprotegido.

É interessante notar que exemplos em que apenas os invariantes são resgatados não vêm facilmente à memória. Relendo The Invisible Man com a atenção voltada em busca de um desses casos, verifica-se que Wells usa constantemente a luz nessa acepção cotidiana. Todavia, essas ocorrências não são marcantes, passando despercebidas em uma leitura que não esteja focada nesse ponto específico. Uma análise mais detida mostra uma aparente intencionalidade de Wells em realçar o aparecimento da luz, na novela, em virtude da centralidade do conceito para o seu argumento principal. Mesmo assim, tais trechos não se tornam tão facilmente recordáveis como os casos de desfamiliarização, os quais provocam experiências mais marcantes, ao exigir a reforma de nossos invariantes. Alguns desses exemplos serão explorados a seguir.

Em The Time Machine, H. G. Wells (1895a) estimula a rever a relação cotidiana com a luz, levando o Viajante no Tempo a uma época na qual parte da humanidade está condenada a viver nos subterrâneos. Os seres que levam sua existência desse modo são os Morlock. Para eles, a luz é sinônimo de ameaça; a escuridão, de segurança e possibilidade de alimento. Por outro lado, para os seres que habitam o mundo iluminado, os Eloi, a relação com a luz é levada a 
extremos. Se, antes, esta significava conforto e segurança, a sua ausência não só retira essa segurança como intensifica sobremaneira o medo e a sensação de perigo. Quando a luz do sol se esvai ao fim do dia, esses seres são vítimas de um pavor extremo, proveniente da certeza de que, se não encontrarem abrigo, algo de terrível acontecerá (WELLS, 1895a, p. 68-86).

O relato do encontro com os seres da superfície pelo Viajante no Tempo, em especial de seu relacionamento com um Eloi, que ele vê como uma moça ${ }^{10}$, chamando-a de Weena, exemplifica bem a dependência dessas criaturas com respeito à luz e seu terror extremo diante da escuridão. Referindo-se a Weena, ele explicita:

Foi através dela, também, que aprendi que o medo não tinha sido extinto naquele mundo. Ela era bastante corajosa durante o dia e tinha uma estranha confiança em mim, porque certa vez, num impulso bobo, fiz trejeitos ameaçadores contra ela, que se limitou a rir. Mas ela temia a escuridão, temia as sombras, temia tudo que fosse escuro. As trevas eram a única coisa que a amedrontava. Era uma reação extremamente intensa, que me deixava meditativo, observando-a. Descobri entáo, entre outras coisas, que aquelas criaturas sempre se reuniam nos grandes edifícios depois de escurecer e que sempre dormiam em grupos (WELLS, 1897b, p. 77-78).

Nesse ponto, o personagem ainda não havia tomado conhecimento dos seres que viviam no subterrâneo, julgando que a humanidade havia se reduzido apenas aos Eloi. Mas ele náo tardou a se defrontar com as criaturas que habitavam a escuridão. $\mathrm{O}$ trecho em que o Viajante no Tempo relata o momento quando se dá conta da bifurcação na evolução humana também exemplifica a relação desses seres com a luz e a escuridão. Ao procurar abrigo do calor excessivo e do sol escaldante ${ }^{11}$, O Viajante no Tempo encontra uma galeria escura:

Em contraste com a luz intensa do lado de fora, naquele local reinava uma escuridão impenetrável. Entrei às apalpadelas, porque a mudança brusca aos olhos criava pontos de luz colorida que dançavam diante de mim. De súbito, parei, estupefato. Um par de olhos, luminosos devido ao reflexo da luz do dia lá fora, me observava das trevas (WELLS, 1897b, p. 80).

\footnotetext{
${ }^{10}$ Vale notar que Wells destaca que é o Viajante no Tempo que a vê como "moça". Ele diz: "encontrei a moça - ou pelo menos era assim que eu a via." (WELLS, 1897a, p. 36)

${ }^{11} \mathrm{O}$ Viajante no Tempo relata que o sol e o calor são bem mais intensos ali do que em sua época, sugerindo um aquecimento do planeta, ao longo dos séculos (ver Wells, 1895a, p. 24).
} 
Cambaleante, enquanto seus olhos se adaptavam à escuridáo, o narrador sente tocar em algo macio:

Virei-me, com o coração aos pulos, e vi uma pequena figura semelhante a um gorila, com a cabeça abaixada de modo peculiar, cruzando o espaço banhado de sol às minhas costas. $\mathrm{O}$ ser esbarrou num bloco de granito, cambaleou, mas instantes depois tinha desaparecido nas sombras debaixo de uma pilha de destroços. (WELLS, 1897b, p. 80).

Claramente o ser se atrapalhava, tendo de se mover na luz e, depois de esbarrar nos escombros, foge para o seu refúgio. O Viajante no Tempo resolve perseguir a criatura, recorrendo à luz de um dos fósforos que leva consigo, para tentar avistá-la mais uma vez: "Acendi um fósforo e, olhando pela boca do poço, vi uma criatura branca, pequena, que descia me fitando com grandes olhos brilhantes. Senti um calafrio. Parecia tanto uma aranha humana!" (WELLS, 1895b, p. 82)

Ao descrever essas criaturas, Wells assume que o ambiente no qual vivem, de alguma forma, condiciona suas características físicas ${ }^{12}$. Os detalhes sobre a evolução desses seres não é o foco aqui, porém, tais características físicas também acabam condicionando sua relação com a luz, na descrição de H. G. Wells. Por exemplo, eles não são adaptados para andar livremente à luz do dia. Seus olhos e pele são vantajosos apenas para a vida subterrânea e para as caçadas na escuridão da noite, já fora das galerias. Caso tentem se aventurar às claras, ficarão fragilizados. Sua segurança é, na verdade, a escuridão, ao contrário do Viajante no Tempo e também dos Eloi.

Enquanto leitores, estranhamos essa nova relação com a luz nos dois casos, de Eloi e Morlocks. Para compreender os Eloi e sentir o que eles sentem, somos forçados a mudar o modo como vemos a luz: exagerar a segurança diante dela e o terror diante de sua falta. Nossas expectativas com respeito à luz cotidiana, portanto, mudam, e isso é conseguido descontextualizando-a, indicando que, para outros, essa relação pode ser diferente. No caso dos Morlock, sua maneira de se relacionar com a luz é contrária à nossa, ficando ainda mais evidente a modificação que precisamos fazer em nossas expectativas. O mais eficiente na experiência causada por essa desfamiliarização é que o

${ }^{12}$ Provavelmente Wells se baseia em teorias evolucionistas, para insinuar que os mais adaptados ao subterrâneo buscam refúgio e se sobressaem, nesse ambiente, surgindo aos poucos grandes grupos vivendo dessa maneira. Para mais informaçóes sobre as teorias evolucionistas nas obras de H. G. Wells, ver Luckhurst, 2005, p. 33-37 e James, 2012, p. 51-64. 
contexto muda, mas tem uma base fixa: ambos os seres ainda são humanos, o que nos faz estranhar ainda mais tais mudanças, porque, em princípio, se trata de nossa própria espécie. Poderíamos ser Eloi ou Morlock. É, em última análise, de nós mesmos que o livro está falando.

O trecho em que o Viajante chama o ser que vê na galeria escura de "aranha humana" exemplifica esse sentimento. Ele vê algo que parece familiar, estranhamente familiar, a ponto de identificar ali o humano, entretanto, vê outros traços que o fazem alterar as conexôes usuais do humano com seu contexto. Tentando resgatar invariantes para identificar a criatura que vê, ele invoca duas imagens: a do humano e a da aranha. Por fim, é obrigado a quebrar o invariante de humano, abri-lo, mudar as expectativas com relação a ele e reformular o conceito de humano. Wells ainda acrescenta à fala do personagem que ele sente "um calafrio" ante essa imagem estranhamente familiar, sugerindo o terror que deparar-se com esse destino de nossa espécie pode causar.

Esse processo parece assemelhar-se ao que Shklovsky define como desfamiliarização. Para explicitar esse conceito, Shklovsky (1917) usa um exemplo de Tolstói, no livro Kholstomer, em que a história é contada do ponto de vista de um cavalo. Em particular, a noção de posse é colocada em xeque nesse trecho, de sorte que Tolstói, por meio da desfamiliarização, nos obriga a reconstruir essa noção. O cavalo reflete sobre a palavra "meu", observando que alguns que o chamam "meu cavalo" não montam nele, outros sim; que alguns são amáveis com ele, outros não (em geral, os mais amáveis não o chamam de "meu") (SHKLOVSKY, 1917, p. 7). Ao final de várias reflexões como essas, o cavalo conclui:

\begin{abstract}
À medida que minhas observaçóes avançavam, no entanto, tornei-me mais e mais convencido de que esse conceito de "meu" era inválido, não apenas para nós, cavalos, mas também para pessoas humanas, isto é, que ele representa nada mais que o instinto básico e bestial do homem de reivindicar propriedade para si mesmo (TOLSTÓI, apud SHKLOVSKY, 1917, p. 7, tradução nossa).
\end{abstract}

Enfatiza Shklovsky (1917, p. 6, tradução nossa): "A estratégia de Tolstói consiste em não chamar as coisas pelo nome, mas descrevê-las como se fossem percebidas pela primeira vez." Ao se deparar com um cavalo explicitando sua incapacidade em compreender por que os seres humanos o chamavam de "meu cavalo", ou por que usavam essa palavra "meu" para coisas e para pessoas, o 
leitor desperta e é levado a rever e questionar o conceito de posse, tấo arraigado na sociedade, que passa despercebido na vida comum.

A estratégia de Wells se parece com a de Tolstói, em Kholstomer, mas não é exatamente a mesma. Na desfamiliarização descrita por Shklovsky, especificamente no exemplo das reflexôes do cavalo em Kholstomer, vamos em busca do conceito de posse e de como o usamos no cotidiano, e este já está muito automatizado para nós. Somos obrigados então a revê-lo, pois ele é colocado em outro contexto, no livro. Por sua vez, alguns objetos com que nos deparamos na ficção científica não são familiares e procuramos neles algo de familiar. Vamos em busca de algum invariante que conhecemos, quase o reconhecemos, porém, é preciso um esforço a mais. Pode-se concluir que, na ficção científica, a percepção se torna ainda mais laboriosa, quando é preciso mais esforço para reconhecer o familiar em seres e objetos estranhos.

\section{OBJETOS CIENTífICOS NA FICÇÁO}

$\mathrm{Na}$ experiência com objetos científicos, na literatura, também é possível identificar os dois tipos de processos descritos para o caso dos objetos cotidianos. Eles podem aparecer apenas causando resgate de invariantes, náo mudando suas conexôes comuns. Por exemplo, seria o caso de uma história que trata de uma teoria científica já existente, não sugerindo nenhuma diferença em nossa experiência com ela. Por outro lado, os objetos e teorias científicas também podem aparecer de modo a provocar o processo de desfamiliarizaçáo, ocasionando a reabertura dos invariantes construídos desses objetos.

É importante considerar que há diferentes graus de contato do sujeito com objetos científicos, dependendo de sua experiência anterior com eles. Para alguns, pode ser que a ideia de espaço-tempo, utilizada em The Time Machine, seja algo já estabelecido, enquanto, para outros, ela pode causar desfamiliarização, ao ser aventada pela primeira vez. Em certa medida, é preciso igualmente levar em conta que isso ocorre com objetos cotidianos. Essas diferenças na experiência podem decorrer da época, local e cultura em que o sujeito está inserido, por exemplo. No caso dos conceitos científicos, contrastes desse tipo podem também ser causados pelo grau de contato com a ciência, bem como com uma área ou teoria científica específica. 
Pode-se dizer que os textos de H. G. Wells são voltados para um público interessado em ciência, mas não extremamente especialista ${ }^{13}$. É possível identificar parte do público-alvo, em The Time Machine, através dos ouvintes do Viajante no Tempo, no primeiro capítulo do livro. Dentre esses ouvintes, estão representados alguns perfis dos possíveis interessados no tema: um psicólogo, um médico, o prefeito etc. Já em The Invisible Man, na explicação teórica feita por Griffin, nos capítulos finais, o médico Dr. Kemp pode ser tomado como o público possível de Wells. Alguém com alguma base em física, mas que não é especialista no assunto.

No caso de ambas as novelas usadas como exemplo, não há necessidade de conhecimento avançado em matemática ou física, uma vez que as explicaçóes são feitas de maneira clara, sendo perfeitamente possíveis de ser acompanhadas com uma base mínima. Em The Time Machine, por exemplo, o Viajante pressupóe conhecimento de geometria euclidiana, mas, mesmo assim, faz uma breve explicação que esclarecerá também aos leitores menos familiarizados com o tema. De posse dos princípios básicos, todos terão igualdade de condiçóes para ir além, no momento da desfamiliarização, dando o salto que modificará as expectativas e fará rever o objeto científico, embora recém-construído para o leitor. Portanto, esse processo irá ocorrer, mais cedo ou mais tarde. Ele pode acontecer já no momento de conceber a geometria quadrimensional ou, apenas mais adiante, no momento de rever a conceituação de tempo. Pode se dar ao compreender as leis da refração e reflexão, ou apenas mais tarde, quando da revelação da grande descoberta que torna a invisibilidade teoricamente possível. Enfim, o processo certamente irá ocorrer, quando os experimentos forem levados a cabo. É experienciando que o tempo se comportou na ficçáo de forma diferente da usual, tendo como consequência a viagem no tempo, ou que a matéria de fato teve sua estrutura alterada, quando a fórmula da invisibilidade foi aplicada, que se completa a desfamiliarização com relação aos conceitos apresentados.

A fim de reforçar as ideias aqui apresentadas, serão explorados dois exemplos de uso de conceitos científicos em H. G. Wells, retirados das obras The Time Machine e The Invisible Man.

Em The Time Machine, a viagem no tempo pressupóe a hipótese científica do espaço-tempo (WELLS, 1895a, p. 3-6). Essa teoria ainda não

\footnotetext{
${ }^{13}$ Simon James sugere que Wells tinha em mente um leitor com gosto acima da média, preparado para inovaçóes em literatura (ver James, 2012, p. 10). James aponta também a importância dada por Wells para a cultura científica, propondo sua uniāo com a artística (ver James, 2012, p. 13).
} 
estava consolidada, mas se sabe que Wells acompanhava o desenvolvimento da ciência da época, inclusive através de revistas científicas. Segundo Tavares, a conferência de Simon Newcomb, citada em The Time Machine, provavelmente se refere a uma conferência real sobre a possibilidade de concepção de uma geometria quadridimensional, ministrada em 1893 e publicada na revista Nature, em 1894 (WELLS, 1895b, p. 165, nota de tradução 1).

Nessa novela, Wells empreende já de início a explicação teórica sobre a possibilidade da viagem no tempo, no trecho em que o Viajante no Tempo está reunido com alguns colegas, dentre eles o narrador da história. Nas páginas 3 a 6, o Viajante, em um diálogo que lembra o socrático, tenta convencer os colegas de que a teoria de base de seu experimento é fundamentada (WELLS, 1895a, p. 3-6). Através da voz desse cientista, o próprio Wells está trabalhando no convencimento do leitor sobre o mesmo ponto. E esse ponto gira em torno da aceitação da noçáo de espaço-tempo e também de certas características da quarta dimensão da realidade, além da relação da consciência humana com ela.

O intuito do Viajante no Tempo é persuadir seus ouvintes de que são quatro as dimensóes dos objetos reais, sendo que a quarta dimensão é em geral negligenciada pela nossa percepção:

- Parece-me claro - prosseguiu o Viajante no Tempo - que qualquer objeto, para ser real, deve se estender em quatro direçōes: deve ter Altura, Largura, Espessura e... Duração. Porém, devido a uma limitação natural dos nossos sentidos, que já explicarei, desprezamos este último aspecto. Existem, na verdade, quatro dimensôes, três das quais constituem os três planos do Espaço e uma dimensão adicional, o Tempo. Temos, no entanto, a tendência a estabelecer uma distinção enganosa entre as três primeiras e a última, porque nossa consciência se move de maneira intermitente em uma direção só, ao longo do Tempo, desde o começo até o fim da nossa vida (WELLS, 1895b, p. 16, grifo do autor).

Até esse ponto, as ideias de Wells, apesar de ainda não totalmente incorporadas ao paradigma vigente na física, não ultrapassam o que já estava no ar, na ciência da época. Wells desfamiliariza essas concepções, quando examina a dimensão do tempo sob uma ótica especial, argumentando que o movimento através do tempo é possível:

Nossa existência mental, que é imaterial e não tem dimensóes, percorre a dimensáo do Tempo a uma velocidade uniforme desde o berço até o túmulo. Do mesmo modo como estaríamos em movimento constante de 
descida se começássemos nossa existência cem quilômetros acima do solo (WELLS, 1895b, p. 19).

O Viajante declara: "É um erro afirmar que não podemos nos mover no Tempo.” (WELLS, 1895b, p. 19). Sublinha que o gérmen de sua descoberta está justamente aí: "[...] por que motivo não pode ele imaginar que um dia será capaz de acelerar ou interromper seu deslocamento ao longo da dimensão do Tempo, ou mesmo retornar e viajar no sentido contrário?” (WELLS, 1895b, p. 20). Essa pergunta é o clímax do processo; é o momento em que o leitor se expóe, epistemologicamente, para mudar expectativas em relação ao conceito científico de tempo. É a partir da quebra das associaçóes e leis científicas usuais para com a dimensão do tempo que surge a possibilidade de viagem no tempo, e o restante da história pode entáo se desenvolver.

Completando o processo, o resultado experimental é a maior arma de convencimento sobre a confirmação da teoria física em jogo. A experimentação é necessária à teoria, não tendo sido realizada na física até então. É preciso quebrar várias expectativas para imaginar como possível essa confirmação experimental, a qual é também o clímax de outra novela de Wells, The Invisible Man. Nela, ao contrário do livro citado anteriormente, a explicação teórica vem apenas depois que os leitores já se depararam com o resultado do experimento. Mesmo assim, este é mencionado novamente ao final da explicação teórica, completando o processo de desfamiliarização.

Essa explicação teórica está bem detalhada no capítulo "Certain First Principles". Nele, Griffin, pedindo ajuda e encontrando refúgio na casa do Dr. Kemp, seu antigo colega dos primeiros anos de faculdade, explica como chegou à ideia e como iniciou a pesquisa que acabaria por torná-lo invisível. Ele começa explicando que abandonou medicina, curso que iniciou junto com Kemp, para fazer física, passando a se dedicar ao estudo da óptica:

E não fazia nem seis meses que me dedicava àquilo quando a luz atravessou a rede, brilhando, de repente, de maneira ofuscante! Descobri um princípio geral de pigmentos e refração, uma fórmula, uma expressão geométrica envolvendo quatro dimensóes (WELLS, 1897b, p. 113-114).

Griffin conta que, àquela altura, se tratava apenas de uma ideia: 
Mas não se tratava de um método, e sim uma ideia que poderia resultar num método, pelo qual seria possível, sem modificar qualquer outra propriedade da matéria, exceto as cores, em alguns casos, reduzir o índice de refraçáo de uma substância, sólida ou líquida, para o do ar, visando propósitos práticos (WELLS, 1897b, p. 114).

Explicado o propósito do experimento de Griffin, o Dr. Kemp ainda não compreende como ele teria conseguido deixar um ser humano invisível. Griffin inicia então uma explicação básica sobre a refração na óptica. Podese afirmar que, para quem já está familiarizado com tais princípios, tem-se apenas uma revisão dos objetos da ciência, simples resgate de invariantes:

Mas considere que a visibilidade de um corpo depende de sua ação em relaçáo à luz. Um corpo pode absorver a luz, refleti-la, refratá-la, ou as três coisas. Mas se não refletir, não refratar nem absorver a luz, esse corpo não será visível. Você vê uma caixa vermelha e opaca, porque a cor absorve uma parte da luz e reflete o resto, toda a frequência vermelha da luz, na sua direção. Se ela não absorvesse nenhuma parte específica da luz, refletindo a luz totalmente, ela seria vista como uma caixa branca brilhante. Prateada! Uma caixa feita de diamante não absorveria muita luz, nem refletiria muito com sua superfície externa, mas, aqui e ali, onde as superfícies fossem favoráveis, a luz seria refletida e refratada, e você teria uma impressão visual de uma série de brilhos, reflexos e transparências, uma espécie de esqueleto de luz. Já uma caixa de vidro não seria tão brilhante nem tão claramente visível como uma caixa de diamante, porque haveria menos refração e menos reflexáo (WELLS, 1897b, p. 114-115).

Ainda especulando sobre as possibilidades de se diminuir a quantidade de reflexão e refração do corpo em um meio, Griffin continua:

E se você mergulhasse uma lâmina de vidro comum na água, ou mais ainda, se utilizasse algum líquido mais denso do que a água, a lâmina desapareceria quase totalmente, porque a luz que passaria da água para o vidro seria muito pouco refratada ou refletida, quase náo sendo afetada. Ficaria tão invisível quanto o gás de hulha ou o hidrogênio no ar. E precisamente pela mesma razão!

(WELLS, 1897b, p. 115)

Até aí, a explicação apenas retoma propriedades e leis já conhecidas, bem estabelecidas na física. A lei da refração na forma atual se deve a Descartes, tendo sido estudada por Snell e Fermat, sendo portanto bem 
conhecida há séculos, em 1897 (BARTHEM, 2005, p. 3-10). Griffin segue, em sua fala, perseguindo a conclusão de que alguns materiais podem se tornar transparentes, desde que se injete neles alguma substância, como mergulhar uma folha de papel em óleo. Inclusive o corpo humano. Então, começa o processo de quebra de expectativas:

E não é só o papel, mas a fibra de algodão, de linho, de lã, de madeira, e os ossos, Kemp, a carne, Kemp, o cabelo, Kemp, as unhas e os nervos, Kemp. $\mathrm{Na}$ verdade, todos os tecidos que constituem o ser humano, com exceção do pigmento vermelho do sangue, e do pigmento escuro do cabelo, são transparentes e incolores. Só isso basta para que nos tornemos visíveis uns aos outros. Porque, em sua maioria, as fibras de um ser humano náo são mais opacas do que a água (WELLS, 1897b, p. 116, grifos do autor).

É preciso dar um salto epistemológico para imaginar que exista uma fórmula capaz de tornar os tecidos humanos invisíveis no ar. Os grifos que Wells imprime, nesse trecho, além da repetição do nome de Kemp, também reforçam a importância do processo de mudança que acaba de começar. Resolvido o problema dos pigmentos do sangue e dos cabelos, seria possível tornar-se totalmente invisível: "- Sabe os pigmentos vermelhos do sangue? Eles podem ficar brancos, incolores, sem perder qualquer uma de suas funçóes.” Kemp deu um grito de incredulidade e espanto (WELLS, 1897b, p. 117).

A esta altura, o leitor está certamente na mesma situação de Kemp. Como se não bastasse a desestruturaçáo necessária para aceitar a transparência da matéria do corpo humano, devemos alterar profundamente expectativas com relação a propriedades da matéria e dos pigmentos. Griffin encontrou uma maneira de fazê-los transparentes e, ao saber disso, somos tão sacudidos de nossas crenças científicas quanto Kemp.

Não só a reação de Kemp induz à importância dessa etapa, na obra, como a atitude do próprio Griffin, relatando o momento de sua descoberta, que, segundo ele, foi "arrebatador". "Realizar algo assim seria transcender a própria magia.", frisa Griffin (WELLS, 1897b, p. 118). O uso do termo "magia” aponta para a sugestão de algo ainda desconhecido epistemologicamente para o leitor. Assim, é possível notar o esforço de Wells para realçar esse trecho. De posse de todas as ferramentas essenciais, o leitor compartilha da marcante experiência do cientista revolucionário em modificar teorias científicas estabelecidas. 
No capítulo seguinte, Griffin descreve o experimento levado a cabo, primeiro com um pedaço de tecido, depois com um gato e finalmente com ele mesmo:

Foi horrível. Eu não esperava tanto sofrimento. Uma noite de angústia dilacerante, náuseas e desmaios. Eu cerrava os dentes, sentindo minha pele queimando, meu corpo todo queimando. Mas resisti como pude. Agora eu entendia porque o gato miara tanto até que eu lhe desse o clorofórmio. Por sorte, eu vivia sozinho naquele quarto, sem companhia alguma. Houve momentos em que só me restava soluçar e gemer. Porém mantiveme firme, até que me tornei insensível. Acordei debilitado, no escuro. A dor tinha passado. Achei que ia morrer, mas pouco me importava. Nunca me esquecerei daquele amanhecer, e do horror de ver que minhas mãos pareciam feitas de vidro opaco e perceber que elas iam ficando cada vez mais claras e translúcidas com o passar das horas, até que fui capaz de enxergar através delas o quarto bagunçado, mesmo fechando as pálpebras, também transparentes. Meus braços e pernas foram ficando vítreos, os ossos e as artérias tornaram-se indistintos e desapareceram e a última coisa a sumir foram os pequenos nervos esbranquiçados. Rangi os dentes e aguentei até o fim (WELLS, 1897b, p. 127).

A circunstância da aplicação do experimento no próprio cientista é cuidadosamente descrita como bastante dolorida e demorada, o que ajuda a deixá-lo marcado junto com a experiência de se estar presenciando e experienciando a aplicação bem-sucedida da teoria. Nesse sentido, o processo pode ser comparado ao que Shklovsky descreve como desfamiliarização, pois torna a percepção um processo longo e laborioso. É uma das ocasióes em que o leitor precisa lutar com os trechos do livro, os quais náo passam pela leitura despercebidos.

Ao acompanhar o sofrimento de Griffin, que é parte de um experimento científico, somos expostos à confirmação experimental das ideias que acompanhamos passo a passo. Com essa descrição, Wells fornece ao leitor, em um processo longo e laborioso, o ponto final da desfamiliarização com relação a certos objetos científicos. A matéria, o corpo humano, os pigmentos, a luz, a refração, tudo precisa ser revisto e reformulado. Pode-se dizer que a transformação de Griffin representa a dificuldade da transmutação de nossas ideias e dos objetos cotidianos e científicos construídos anteriormente. 


\section{CONSIDERAÇÓES FINAIS}

Após o exame da exposição feita neste artigo, conclui-se que é possível relacionar a construção de objetos presentes nas obras literárias com o processo de resgate de invariantes e com a construção de objetos científicos. É razoável afirmar também que a adiçãoo da desfamiliarização, conforme descrita por Shklovsky e expandida por Banes, é necessária para uma melhor compreensão do processo.

Sugere-se que, em alguns casos, o objeto literário resultante da desfamiliarização retoma sensações, quando resgata objetos cotidianos. $\mathrm{Ou}$ seja, o objeto do contexto literário não é constituído de pura configuração. Ele resgata invariantes, mas os modifica, obrigando à reconstrução do objeto, resgatando também o contato com as sensaçôes que o constituem. Não se trata de um contato imediato, como no caso da construçáo da realidade cotidiana, mas de um contato mais profundo do que apenas reconhecimento. Trata-se de um processo especial, que traz um tipo de revisitação da sensação, típica da arte e peculiar da leitura de literatura.

Alguns trechos de Shklovsky reforçam essa interpretação. Por exemplo, quando o autor se refere à capacidade da arte de nos fazer sentir os objetos novamente: fazer uma pedra parecer pedra, ser sentida como pedra etc. Essas afirmaçôes dão a entender, juntamente com o restante da argumentação de Shklovsky em torno da revitalização da percepção, que há um retorno às sensaçôes, nesses momentos, fazendo-nos conscientes delas.

Banes também reforça a ideia de que a desfamiliarização é uma estratégia para revigorar a percepção, conforme foi visto ao longo deste texto. A autora cita vários exemplos relativos à dança, nos quais os espetáculos se utilizam da repetição e releitura de atitudes cotidianas, até que se passe a estranhá-las. Pode-se sustentar que passamos a vê-las com mais clareza. Como na performance Water, de Robert Whitman:

Water, uma performance multimídia que ocorreu em uma estrutura temporária em uma rua particular em Los Angeles, envolveu uma grande quantidade de água e muitas atividades envolvendo lavar. Tomar um banho e fazer a barba são os eventos mais cotidianos; mangueiras, câmaras de ar e baldes sáo os objetos mais ordinários. Ainda assim, da maneira com que foram reunidos, particularmente seus ritmos e rimas, eles se tornaram estranhos [unfamiliar]: estranhamente evocativos, poéticos e oníricos, misturando corpos humanos e objetos, de uma maneira surrealista (BANES, 2003, p. 5, tradução nossa, ênfase da autora). 
A recontextualização também é frisada por Banes como importante para o processo. Contudo, a desfamiliarização não resulta apenas de deslocamento de contexto. Muitos objetos são deslocados de contexto para a literatura, através do resgate de seus invariantes, não resultando na experiência da desfamiliarização, conforme visto em alguns exemplos. $\mathrm{O}$ mesmo ocorre com objetos científicos. Além disso, a própria construção de objetos científicos pode se dar no momento da leitura de ficção. Em geral, esta acontecerá para embasar cientificamente o leitor e assim possibilitar a desfamiliarizaçáo do conceito científico. A fim de que a desfamiliarização ocorra, no entanto, é preciso algo mais: um trabalho em direção à quebra de expectativas e mudança nas conexôes usuais.

É interessante notar que a desfamiliarização pode envolver objetos cotidianos e científicos, ao mesmo tempo, como no caso do trecho no qual Wells descreve a transformação de Griffin em Homem Invisível. Acompanhála exige tanto mudanças com relação a conceitos científicos quanto cotidianos; na cena da transformação, estes se confundem, sendo que somos expostos e absorvemos as alteraçôes nos dois âmbitos, ao mesmo tempo.

Relacionando o processo de desfamiliarização descrito e exemplificado por Shklovsky e Banes, este artigo sugere que é possível identificar um tipo específico de desfamiliarização na ficção científica. Nas obras desse gênero, muitas vezes coisas estranhamente familiares aparecem, nossa busca por elas em nosso banco de invariantes fracassa e somos obrigados a mudá-los. Mudar esses invariantes pode nos aproximar novamente das sensaçôes, além de nos fazer viver experiências, como se fosse a primeira vez. Essa mudança gera reflexão e causa um sentimento de terror diante das possibilidades que se abrem. Além disso, pode trazer o discernimento sobre algo até então velado. Desautomatizamos a vida, enxergando-a de fato, depois dessas experiências.

Os exemplos apresentados corroboram essas afirmaçôes. Por vezes, estranhamos a vida através da simples reflexão sobre um objeto comum, como nas obras de Tolstói. Esse estranhamento traz reflexôes profundas, sem dúvida. Outras vezes, esse estranhar vem do deslocamento de contextos trazido pela ficção científica, tendo consequências profundas e marcantes em nossa experiência. Às vezes, é preciso imaginar que seja possível tornar-se invisível para estranhar o que é ser humano, o que é o corpo, o que é a matéria que compóe o universo ou mesmo o que săo as leis que a ciência apresenta como verdadeiras. Outras vezes, é preciso imaginar possível a viagem no tempo, para que possamos refletir sobre o que significam realmente as instituiçóes e os 
costumes que perpetuamos e a que ponto eles poderiam ser mudados; não são, na verdade, fixos, como éramos tão automaticamente levados a pensar. Ver o humano nos Eloi e nos Morlock nos faz rever nossa identidade enquanto seres humanos. A experiência dessas leituras nos faz pensar se somos capazes de agir como Griffin, ou como seria ser Morlock.

Uma série de reflexôes pode emergir nesses casos, como questóes morais e éticas, políticas, sociais etc. Em nossa pesquisa, enfatizam-se as considerações epistemológicas e ontológicas, além de estéticas e científicas. Todavia, salientase a importância de que a desfamiliarização na ficção científica também seja utilizada como ferramenta para se repensar outras questôes de grande importância. É difícil separá-las - o que é feito neste artigo, para fins de estudo. A não fragmentação da experiência humana reforça a genialidade desses autores e autoras de literatura de ficção científica, os quais nos ajudam a desfamiliarizar nosso próprio universo e nossos padróes, sejam eles morais, sejam éticos, políticos, racionais ou científicos. A leitura de uma frase pode ser o ápice de um processo que nos deixa, repentinamente, conscientes e atentos, despertando para questionar o aparentemente inquestionável.

MURR, C. E. Defamiliarization and science fiction: a schrodingerian approach to the construction of the literary object. Trans/form/ação, Marilia, v. 43, n. 3, p. 35-64, Jul./Set., 2020.

\begin{abstract}
This paper approaches the construction of literary objects in human experience, based on Schrödinger's ideas on the construction of reality, published between 1928 and 1964. It is suggested relating the construction of such objects to the Schrödingerian account of the processes of invariants' retrieve and construction of scientific objects. Nevertheless, such approach doesn't seem sufficient to explain certain cases. Hence, the addition of the notion of defamiliarization, advanced by Shklovsky in 1917 and revisited by Banes in 2003, is proposed. This conception consists basically in making familiar things strange, driving attention towards its direction, through a memorable experience. Defamiliarization seems adequate to describe moments in which expectations are broken and a return to sensations is observed. This article also explores some examples that illustrate those processes. Some fragments of H. G. Wells's works are examined and scientific objects that are restored on fiction are emphasized. Such analysis indicates that these objects are also submitted to defamiliarization, however differently from quotidian objects. Besides, some of the examined texts indicate that defamiliarization is intensified in Science Fiction reading.
\end{abstract}

Keywords: Schrödinger. Invariants. Defamiliarization. Science Fiction. H. G. Wells. 


\section{REFERÊNCIAS}

ASIMOV, I. Understanding Physics. Light, Magnetism, and Electricity. Vol. II. Chicago: A Mentor Book, New American Library, [1966] 1969.

BANES, S. Gulliver's Hamburguer: Defamiliarization and the Ordinary in the $1960 \mathrm{~s}$ Avant-Garde. In: BANES, S. (ed.), Reinventing Dance in the 1960s. Everything was possible. Madison: The University of Wisconsin Press, 2003, p. 3-23.

BARTHEM, R. A luz. 1a Edição. Coleção Temas Atuais de Física. São Paulo: Livraria da Física Editora, 2005.

DEWEY, J. Art as experience. New York: Perigee, [1934] 2005.

ELGIN. C. Making Manifest: the role of exemplification in Science and the Arts. In: DUTRA, L. H. (ed.), Principia, Revista Internacional de Epistemologia, Vol. 15 n. 3, dez. 2011, p. 399-413. Florianópolis: Núcleo de Epistemologia e Lógica, Universidade Federal de Santa Catarina, 2011.

JAMES, S. J. Maps of Utopia. H. G. Wells, Modernity \& the End of Culture. New York: Oxford University Press, 2012.

LUCKHURST, R. Science Fiction. Cambridge: Polity Press, 2005.

MURR, C. E. Física Quântica e Objetividade Científica: Algumas ideias filosóficas de Erwin Schrödinger. 2010. 162p. Dissertação (Mestrado em Filosofia). Universidade Federal de Santa Catarina, Programa de Pós-Graduação em Filosofia, Florianópolis, 2010.

LUCKHURST, R. A realidade através do espelho: Schrödinger e Russell no País da Objetivação. 2014. 323p. Tese (Doutorado em Filosofia). Universidade Federal de Santa Catarina, Programa de Pós-Graduação em Filosofia, Florianópolis, 2014.

PASSOS, C., RIAUDEL, M., \& ROSENBAUM, Y. Dossiê Figuras do estranhamento. In: Literatura e Sociedade, 20(20), 81-84. 2015.

Disponível em: <https://doi.org/10.11606/issn.2237-1184.v0i20p81-84>

RUSSELL, B. The Analysis of Mind. New York: Watchmaker Publishing, [1921] 2010.

SCHRÖDINGER, E. Conceptual Models in Physics and their Philosophical Value. In: SCHRÖDINGER, E. Science and the Human Temperament. Tradução de W. H. Johnston. London: George Allen \& Unwin Ltd, [1928] 1935, p. 119-138.

SCHRÖDINGER, E. Science and Humanism: Physics in Our Time. In: SCHRÖDINGER, E. "Nature and the Greeks" and "Science and Humanism". Cambridge: Cambridge University Press, [1951] 1996, p. 101-172.

SCHRÖDINGER, E. Science, Philosophy and the Sensates. In: BITBOL, M. (org.). "The Interpretation of Quantum Mechanics: Dublin Seminars (1949-1955)" and Other Unpublished Essays. Woodbridge: Ox Bow Press, [1954a] 1995, p. 123-130. 
SCHRÖDINGER, E. Nature and the Greeks. In: SCHRÖDINGER, E. "Nature and the Greeks" and "Science and Humanism". Cambridge: Cambridge University Press, [1954b] 1996, p. 3-99.

SCHRÖDINGER, E. Mind and Matter: the Turner Lectures. In: SCHRÖDINGER, E. "What is life?" with "Mind and Matter" and "Autobiographical Sketches". Cambridge: Cambridge University Press, [1956] 2001, p. 93-164.

SCHRÖDINGER, E. What is an Elementary Particle. In: SCHRÖDINGER, E. Science, Theory and Man. Tradução de J. Murphy e W. H. Jonston. New York: Dover Publications, 1957, p. 193-223.

SHER, B. Shklovsky and the Revolution. Translator's Introduction. In: SHKLOVSKY, V., [1917], Theorie of Prose. Champaign: Dalkey Archive Press, 1990.

SHKLOVSKY, V. Art as Device. In: SHKLOVSKY, V. Theory of Prose. Tradução de B. Sher. Champaign: Dalkey Archive Press, [1917] 2009, p. 1-14.

TAVARES, B. Prefácio. In: WELLS, H. G. A Máquina do Tempo. Rio de Janeiro: Editora Suma, 2018, p. 5-11.

WARHOL, A. Brillo Box (Soap Pads). Synthetic polymer paint and silkscreen ink on wood. Dimensions $171 / 8$ x 17 x 14" (43.3 x 43.2 x $36.5 \mathrm{~cm})$. New York, The Museum of Modern Art, 1964.

WELLS, H. G. The Time Machine. New York: Dover Publications Inc, [1895a] 1995.

WELLS, H. G. A Máquina do Tempo. Tradução de Braulio Tavares. Rio de Janeiro: Editora Suma, [1895b] 2018.

WELLS, H. G. The Island of Dr. Moreau. New York. Dover Publications Inc, [1896] 1996.

WELLS, H. G. The Invisible Man. E-book. Project Guttemberg, [1897a] 2004.

Disponível em: http://www.gutenberg.org/ebooks/5230. Acesso em 11 ago. 2017.

WELLS, H. G. O Homem Invisível. Tradução de Bruno Alexander. Porto Alegre: Ed. L\&PM, [1897b] 2017.

Recebido: 28/01/2019

Aceito: 22/02/2020 